\title{
Formative research on factors influencing access to fistula care and treatment in Uganda
}

Pooja Sripad

Population Council

Charlotte E. Warren

Population Council

Follow this and additional works at: https://knowledgecommons.popcouncil.org/departments_sbsr-rh

Part of the Demography, Population, and Ecology Commons, Family, Life Course, and Society Commons, International Public Health Commons, Maternal and Child Health Commons, and the Women's Health Commons How does access to this work benefit you? Let us know!

\section{Recommended Citation}

Sripad, Pooja and Charlotte E. Warren. 2016. "Formative research on factors influencing access to fistula care and treatment in Uganda." Washington, DC: Population Council. 


\section{ON FACTORS INFLUENCING} ACCESS TO FISTULA CARE AND TREATMENT

\section{IN UGANDA}

Pooja Sripad

Charlotte Warren

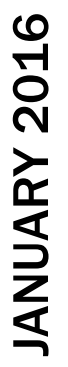




\section{Table of Contents}

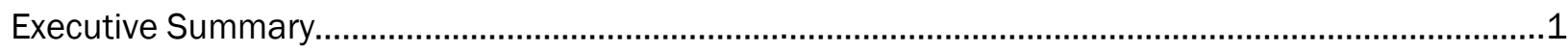

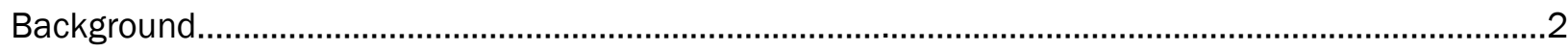

Methods of data collection, sampling, analysis..............................................................................

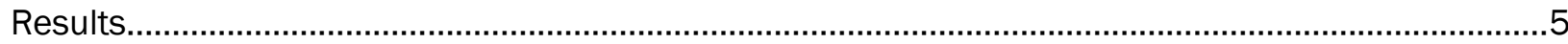

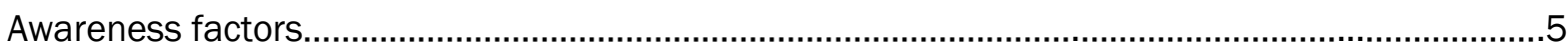

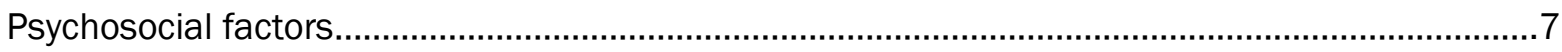

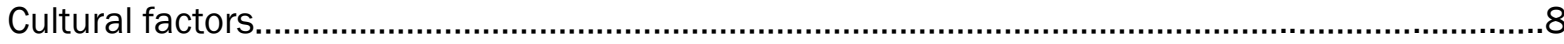

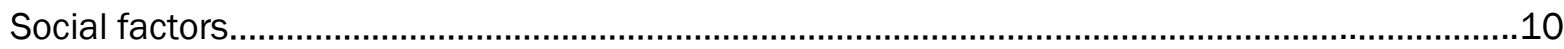

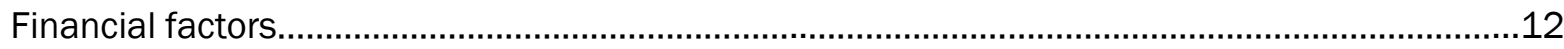

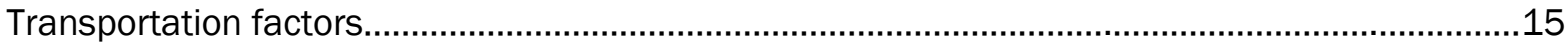

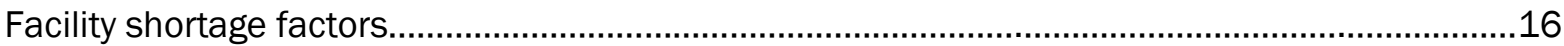

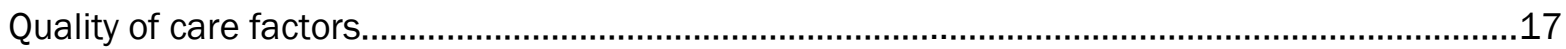

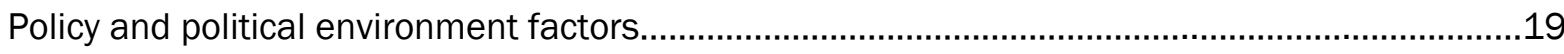

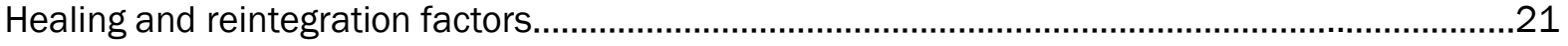

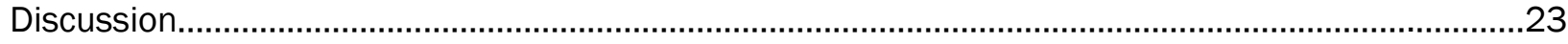

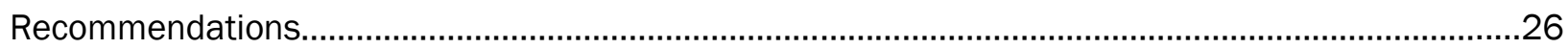

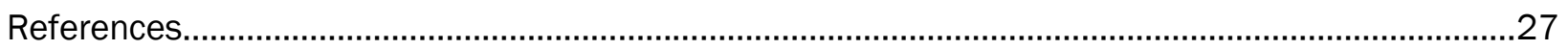




\section{Acronyms}

$\begin{array}{ll}\text { ANC } & \text { Antenatal Care } \\ \text { D\&A } & \text { Disrespect and Abuse } \\ \text { FGD } & \text { Focus Group Discussion } \\ \text { HM } & \text { Head Matron } \\ \text { IDI } & \text { In-Depth Interviews } \\ \text { MOH } & \text { Ministry of Health } \\ \text { OF } & \text { Obstetric Fistula } \\ \text { PWD } & \text { People with Disabilities } \\ \text { RMC } & \text { Respectful Maternity Care } \\ \text { RMNCH } & \text { Reproductive Maternal Newborn Child Health } \\ \text { UDHS } & \text { Uganda Demographic and Health Survey } \\ \text { UTI } & \text { Urinary Tract Infection } \\ \text { VHT } & \text { Village Health Team }\end{array}$




\section{Executive Summary}

This formative research builds upon the results of a systematic review for better understanding of the barriers and enabling factors for fistula repair care and access in Uganda. Understanding how Ugandan women living with fistula decide to seek care, identify and reach medical centers, and receive adequate and appropriate care is a necessary step in the implementation research process for designing an evidence-informed intervention. The study focuses on Fistula Care Plus project-supported treatment facilities where fistula camps are routinely held. Seventy-three in-depth interviews (IDIs) and eight focus group discussions (FGDs) were conducted in Hoima and Masaka, in and around Hoima Regional Referral Hospital and Kitovu Mission Hospital, respectively, from October to December 2015. The data captured a range of perspectives from those with personal or professional fistula experience, for both individual and group narratives of the experiences of those affected by fistula in Uganda.

Results reveal the nuances of women's experiences, along with the additional perspectives of their spouses, family members, community stakeholders, and fistula camp care providers including nurses-counselors, surgeons, and facility and district managers. Barriers and enablers to fistula repair care are clustered around the following factors: psychosocial, cultural, social, financial, transportation, facility shortages, quality of care, awareness, policy and political environments, and healing and reintegration. The nuances within each of these categories reveal cross-cutting challenges such as poverty, limited education, gender dynamics, social norms, and political structures affecting fistula prevention and treatment.

The range of barriers and enablers suggest that it is critical to focus on awareness, transportation, and financial barriers to care, given their importance to other Fistula Care Plus initiatives beyond their implications for fistula prevention and treatment access. The findings suggest there are research gaps, including the need for a barrierenabler index, to be tested, for assessing the relative influence of each factor on access to timely repair care, as well as incorporating the perspectives of providers working at lower level health facilities. Finally, recommendations for policy and practice reinforce the need for targeted programming strategies to increase access for obstetric fistula repair, including promote community-based referrals, increased funding, gradual progress in institutionalizing repair care opportunities, advocacy for respectful maternity care, as a part of prevention, and incorporating obstetric fistula information into young people's health education. 


\section{Background}

This study presents qualitative findings from formative research on the barriers and enabling factors for fistula treatment in Uganda, building on barriers identified in a systematic review of the literature, and examining how these broad factors manifest in Hoima and Masaka districts in Uganda, where fistula camps are held three or four times a year. In Uganda fistula camps are standard practice, although routine fistula repair is available at Mulago Hospital in Kampala. As is evident in the data, these procedures are a lesser priority for the health system and therefore are not a viable source of care for many women suffering from this condition. This report describes data collection, sampling, and results, with supporting quotations describing the factors that influence fistula treatment access. The report concludes with a short discussion of feasible interventions and recommendations based on the data derived from this study.

The preceding systematic review of peer-reviewed and 'grey' literature (Bellows et al. 2015) identified 110 studies related to addressing barriers to accessing obstetric fistula (OF) repair care in developing countries. The articles reveal clustering of those barriers in nine broad areas-psychosocial, cultural, awareness, social, financial, transportation, facility shortages, quality of care, and political-corresponding with the Three Delays Model (Thaddeus and Maine 1994). The Three Delays Model classifies and describes the underutilization of maternity services that drives mortality and morbidity due to 1 ) the delay of the decision to seek care by an individual or families, 2) the delay in reaching an adequate health facility, and 3) the delay in receiving adequate care once at a facility.

\section{Figure 1: Three Delays Model to Fistula Care}

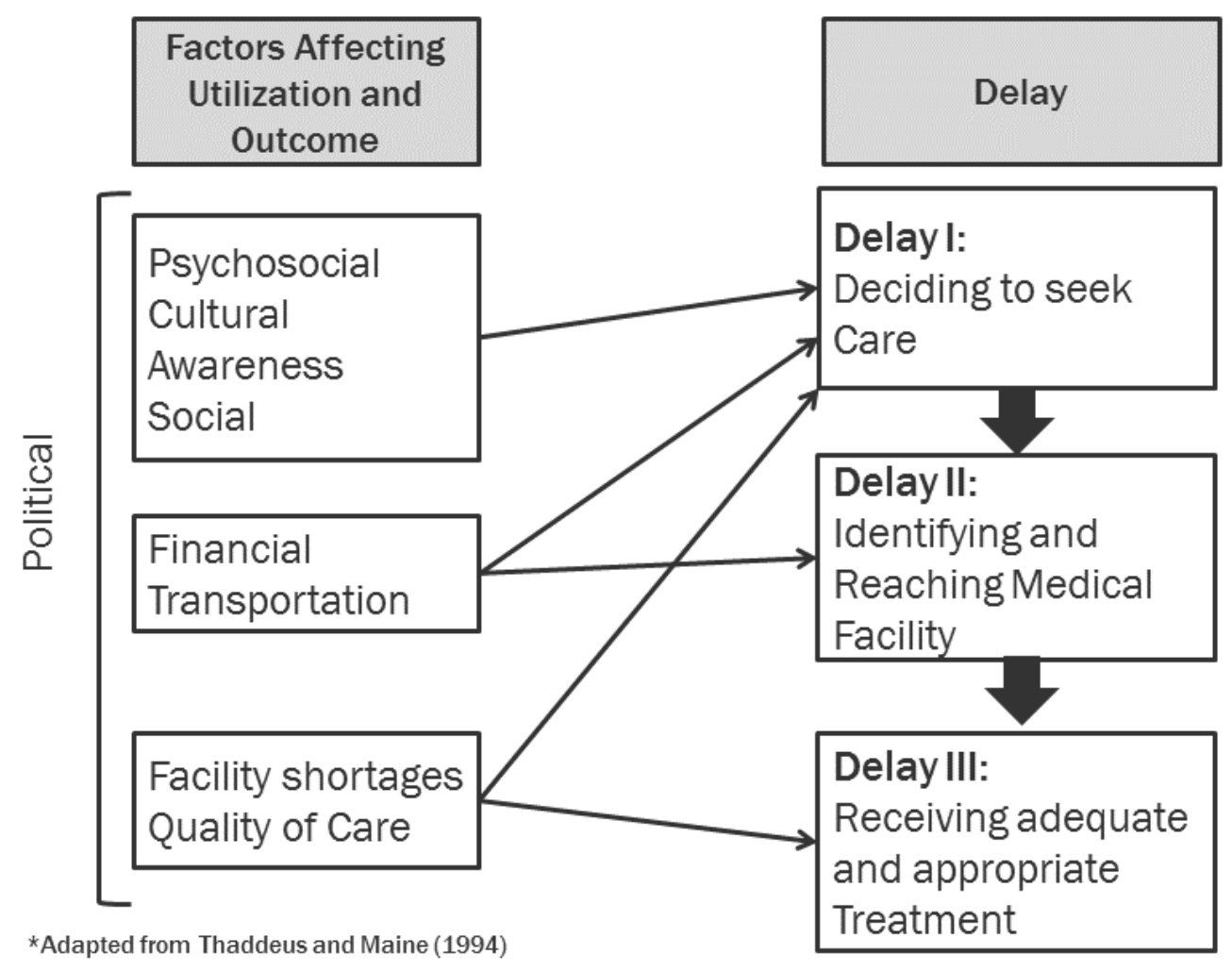


Geographically sparse fistula repair coverage in Uganda further complicates and affects each delay, into which each barrier to care can be grouped. The systematic review showed that OF is further linked to poverty, income inequality, gender disparities, discrimination, and low education, and there is a dearth of studies evaluating intervention strategies that the target first, second, and third delays-in part due to OF's low prevalence compared to other priority health areas, high cost repair procedures, and the complexity and variability of postrepair prognosis.

In Uganda, a priority shift catalyzed by the Fistula Care Plus consortium of the government, donors, and society propelled national efforts for enhancing sexual and reproductive health (SRH), of which OF is an important aspect. According to the Ministry of Health's (MoH) National Obstetric Fistula Strategy 2010/2011 - 2014/2015 and the Ugandan Demographic Health Survey (UDHS 2006), OF burden is most prevalent in women living in Uganda's Western and Central regions.

\section{Study objectives}

This formative research by Population Council identified barriers and enablers of repair care for informing the design of an implementation research study that will develop, implement, and test an intervention addressing barriers to fistula care access. Formative research participants were recruited in Hoima (Western) and Masaka (Central) regions. 


\section{Methods of data collection, sampling, analysis}

Seventy-three in-depth interviews (IDIs) and eight focus group discussions (FGDs) in Hoima and Masaka, in and around Hoima Regional Referral Hospital and Kitovu Mission Hospital, respectively, from October to December 2015 , captured a range of perspectives of those with personal or professional OF experience. IDIs included women affected by OF (post-repair clients, clients awaiting repair, clients living with fistula, spouses and other individuals accompanying clients to repair centers, providers at fistula camps (ANC staff, fistula nursescounselors, fistula surgeons), facility managers, and district staff (head matrons, district managers). FGDs were conducted with post-repair clients and community stakeholders (men and women).

Table 1. Sample breakdown

\begin{tabular}{|l|c|c|c|}
\hline & Hoima & Masaka & Total \\
\hline IDIs & 40 & 33 & 73 \\
\hline Women affected by fistula & 20 & 15 & 32 \\
\hline Spouses and other accompanying family members & 6 & 5 & 11 \\
\hline Providers at camps & 10 & 10 & 20 \\
\hline Facility and district management & 4 & 3 & 7 \\
\hline FGDs & 4 & 4 & 8 \\
\hline Post-repair clients & 2 & 2 & 4 \\
\hline Community stakeholders - women & 1 & 1 & 2 \\
\hline Community stakeholders - men & 1 & 1 & 2 \\
\hline Total & & & 80 \\
\hline
\end{tabular}

Data were collected primarily in Luganda, although some participants responded in Runyoro (in Hoima). Participants were 17 to 53 years old, and of those who reported their ages during IDIs, most were married, while nine were separated or divorced, one was widowed, and four never married. Most women affected by fistula had attended primary school, at most, and a good proportion worked as farmers in their villages-providers confirmed similar demographics in their client populations. The data show the occurrence of a variety of fistula types including iatrogenic, traumatic, and obstetric.

IDIs with women affected by OF showed that 23 (15 in Hoima, 8 in Masaka) experienced prolonged labor, due to delayed labor and delivery care during childbirth (either in getting to a facility or while at facility) and 11 (5 in Hoima, 6 in Masaka) reported cesarean sections for the incident childbirth. Although most women did not appear to have significant co-morbidities at the fistula camp for repair care-as self-disclosed or described by a family member-eight women mentioned at least a discussion of treatment for co-morbidities of urinary tract infections (UTIS) and HIV in Hoima, and for backaches or kidney problems, a tumor, other fistula symptoms, and throatrelated concerns in Masaka.

Interviews were transcribed and translated into English, read, and inductively and deductively coded using Nvivo11 software. The codebook was informed by the systematic review and incorporated thematic areas (e.g. healing and reintegration) that emerged from the data. Factors sorted into barriers and enablers for OF repair were compared both with community and provider perspectives for a comprehensive understanding of fistula issues.

Ethical approval was obtained from Population Council's Institutional Review Board (Protocol 694) and the Research Ethics Committee of Makerere University's College of Health Sciences School of Medicine as well as the Uganda National Council for Science and Technology (UNCST), as HS1921. 


\section{Results}

Prevailing views indicate that barriers and enablers of access to OF repair care are clustered around awareness, psychosocial, cultural, social, financial, transportation, facility shortages, quality of care, policy and political environment, and healing and reintegration factors, which influence, in distinct as well as reinforcing ways, the delay to seek care, delay in reaching care, and delay in receiving care once at a hospital.

\section{Awareness Factors}

\section{Barriers}

Although most community members are aware of the symptoms and challenges faced by women affected by fistula, there is insufficient awareness about the obstetric and non-obstetric causes of the condition, prevention strategies, its treatability, and where and when to seek care. In both Hoima and Masaka, communities described varying degrees of beliefs that fistula is caused by witchcraft, home delivery by traditional birth attendants (TBAs), facility delivery with negligent providers, or cesarean section-particularly if the woman giving birth is "weak," "young," or "too small." There were also misconceptions about which hospitals offer repair care, whether members not of a particular faith will be treated at faith-based hospitals, and whether or not OF is "fixable." Awareness barriers limit the abilities of women, their spouses, and family members to recognize the condition and make the decision to seek repair care, and these awareness factors are often exacerbated by remote residences and access to reproductive, maternal, newborn and child health (RMNCH) information.

"It took a period of about two months to notice this condition because I had never heard about it, that it can happen to a person." IDI, client living with fistula, Hoima

"Some people say that the disease is hereditary and it came way back from their grandmothers, and that they also suffered the same disease, but the old people had not got a chance like this one to be operated, so they would suffer until they die, so I also thought that the disease is hereditary."

$I D I$, client awaiting repair, Masaka

"I think delivering with unprofessional health workers they can tell her to push the baby out before the due time and the baby may end up suffocating the bladder and as an end result the woman may develop fistula...Some lack knowledge of where to come for treatment, others lack a special area for treatment near us. Sometimes they don't hear announcements from the radios due to lack of batteries so they may not know where to go and when."

IDI, spouse, Masaka

"We went to different traditional doctors thinking that she was bewitched but we found out that our money was wasted for nothing when the problem wasn't fixed instead was worsened. We heard some announcements and we came to Mubende hospital for treatment and they told us they couldn't-we should come back home. It was a big problem to us and worsened as she continued to pass urine seriously."

IDI, spouse, Masaka

"We went to a doctor in Masindi and they gave me drugs and I took it-they gave me three weeks and it did not work and we went to another doctor. Then he told us to come to a gynecologist here in Hoima, so I came here-they gave me more medicine and she told me to come to the hospital here."

FGD, post-repair client, Hoima

Insufficient provider awareness, evinced in the final quote, about OF screening and referral for adequate care, manifested as a sub-theme. Despite the fact that most deliveries in this sample occurred in a facility, women were rarely informed of their OF condition, which reveals an awareness gap (for screening) among health centers and lower level health provider cadres. 


\section{Enablers}

A need for health education, post-repair counseling, and information dissemination in communities through various outreach channels (churches, village health teams (VHTs), community meetings, peer educators, leaders, neighbors and word of mouth, phone networks, radio) about the causes, prevention, effects, and treatment of OF emerged unanimously, throughout the various perspectives of respondents. Targeting pregnant women, young people, spouses of women of reproductive age (who likely have more household decision-making power), and those living in remote areas ("deep in the forest") is critical to facilitating access to repair care. Though educational content may vary by target group-providers, clients, and communities describe the need to emphasize the importance of delivering in facilities, dispel myths about facility delivery, including illustrating midwives as non-threatening. Moreover, integrating OF-related information into broader RMNCH education (antenatal and other forums)-beyond camp advertisement-is crucial to building community awareness where mass media communication does not penetrate.

"But when the trainings started we became aware. For me what I have observed is that the whole village knowing that you are the one leaking urine is good-but I am emphasizing to remove fear from someone so that they can come to the health facility...knowing even if you are normal that you can also develop it." FGD, community women, Hoima

"If a person isn't taught how fistula is formed they go with the thinking that it is bewitching in the community; she will think the co-wife is the one bewitching her because they don't know the cause."

IDI, nurse-counselor, Hoima

"Women need to be helped to get proper treatment; hospitals also should go to villages that treat fistula. Also some women should go to communities to encourage them and come to hospitals."

FGD, community men, Masaka (1)

There should be trainings about health issue, I think there are women who don't know anything about fistula at all."

FGD, community men, Masaka (2)

"I talked of trainings in communities about fistula and other disease because one may get fistula and end up with HIV."

FGD, community men, Masaka (3)

"What is done here [for camps] is radio announcements and these radio announcements reach very far. So like when one hears and she knows somebody, a friend or a relative who has this condition, these people also again call. They call like those ones that are very far where the radios don't reach, it's these people from within who hear and inform them, the community now...There is a way the communication has always been over the radios then giving the letters to these mothers that come for antenatal and they take to the churches. So again it the communities that continues to spread that."

IDI, ANC/maternity unit staff, Hoima

"Here we use radios and by using a radio-also we have to give them the telephone number were someone can call and know the information. So our telephone numbers are always on the radios...we want to know this something from Kitovu hospital...so and so will give you the information." IDI, nurse-counselor, Masaka

"In some area where EngenderHealth has trained the health team members, I think communities are doing well but unfortunately the villages are limited. If we can embark on sensitizing village health team members, to mobilize their localities, as far as fistula is concerned, this could work. As we talk now, it is the minimal information they get may be from radio talk shows that is always done when the camp is going to take place. But otherwise, there is need to mobilize communities." IDI, district level manager, Hoima 


\section{Psychosocial factors}

\section{Barriers}

Psychosocial barriers to OF repair are particularly debilitating, as they involve the cognitive processing of social, cultural, awareness, and other contextual circumstances facing women living with OF. These barriers manifest in feelings of depression, anxiety, lack of dignity in living, and loss of hope for recovery. This sense of worthlessness results in low self-esteem ranging from feelings of embarrassment, to stress-induced ulcers, to suicidal ideation, and is often moderated by women's social environments and other health conditions (HIV, foot drop). Additionally, described by communities and providers alike, some women fear visiting health facilities due to fears of medical procedures thought to result in uterine removal as well as mistaken causes of OF, such as cesarean section, in addition to fears of any type of surgery, and harsh or negligent providers. Though generally, psychosocial barriers are framed as a challenging for women, a number of participants in the community and amongst health care providers describe women as 'lazy' as an explanation for not seeking care-this may be in part due to the loss of hope, but likely also relates to cultural, social, and transportation barriers discussed in subsequent sections. While psychosocial distress of younger patients sometimes elicits family empathy, hopelessness ensues profoundly in elder patients who may have had prior operations or "learned to live with it."

"Others fear to be ashamed from hospital it is stigmatizing...One wonders how she will tell the doctors that I am passing urine all the time." FGD, community women, Masaka (9)

"Others may assume that they have sicknesses other than fistula." FGD, community women, Masaka (4)

"You may fear to go in public because of the bad smell you have, you begin to wonder where will you pass to reach hospital...Also not being confident about the self we should seek medical attention pertaining our health...They stay with no peace in life."

FGD, community women, Masaka (2)

"And whatever you put on as clothes you don't look smart."

FGD, community women, Masaka

"Or me I have had a lot of problems as a result of this fistula even up to now the leg even if you pinch me I don't hear anything. For all the years I have lived with it but I walk and also all other diseases are on me I even I attempted to kill myself but people found me with a rope and helped me...So now when I came here I was told I have pressure."

FGD, post-repair client, Masaka (4)

"I used to cry all the time, I spent four years crying and bearing in mind that my sister was mistreating me...I refused to eat but I didn't reach an extent of killing or poisoning myself."

FGD, post-repair client, Masaka

"Yah I used to be worried because I used to wonder of all people God chose only me to suffer like this and I wasn't happy at all."

FGD, post-repair client, Masaka (6)

"Now that is what made her body get even worse and feeling restless because of her mother [dying]...she got used to it there is nothing she can say, apart from saying, I have my disease I have nothing I can do about it...What used to make her cry was the feeling that, 'If my brother was still alive he would have helped or if my mother was still alive, she would gamble and help me.' But they all left her and she remained there in emptiness. Those are the things I see that used to disturb her a lot."

IDI, family member, Hoima

"Normally elderly patients tell us that for me musawo [nurse], I lost hope that I can get cured. Even if you do [encourage repair] they have that on their mind, so most of them are there reason being they know they cannot get better even if they do an operation." IDI, nurse-counselor, Masaka 


\section{Enablers}

Providing psychosocial support for women affected by OF involves relatives and communities enabling management of their condition within their households and motivating care seeking, while reducing attached stigma associated with the condition. Part of this stems from understanding and responding empathetically to the stress felt by suffering women, while part of it stems from better OF understanding.

"Women fear that they are going to remove their uterus. They fear a lot of things and my mother also had started fearing-I told her just be courageous and ready for everything, be strong." IDI, daughter, Hoima “[Relatives] can provide basics like soap." $\quad$ FGD, post-repair client, Masaka (6)

"Those who have enough can share with the patients and also come to hospital to visit them and see how they are."

FGD, post-repair client, Masaka (4)

"They should give encouragement and counseling [kubagumya no kubudabuda]...showing that they aren't the only one with it in the whole world. They shouldn't back bite us or stigmatize us like when you pass them they put fingers on their noses. We didn't like it this way at all." FGD, post-repair client, Masaka (2)

"She had a lot of stress because the leg pained her so much and she would cry, I even put her on the back and I would move around because she could not stand, she would spend the night crying and yelling-this happened for a month...The husband has been good, he has even been sleeping here, if she cried, he would baby seat the child, feed the child as me I would massage the leg, he really never left her. Even her grandfather would spend a night just looking." IDI, grandmother, Masaka

"We see that the way the men are getting educated and people healed or through being talked to it's helpful because of the reason that they have been treated badly. They see being nursed by their child, even the child will reach a point and gets fed up and even this one who is sick feels despised and does not want to go among people. Now you will see that she is disgusted due to lack of peace. But this organization, I thank God for it because it has opened people's eyes and they have started understanding what is going on." FGD, community women, Hoima

\section{Cultural factors}

\section{Barriers}

Cultural barriers affect women's decisions to seek care, ability to reach repair camps or facilities, and their adequate care at facilities. Gender dynamics-namely male dominance-in communities and villages, and within households, manifest in ways that curtail women's agency for seeking care. Often husbands and older family members are primary decision-makers, although many women described at least a somewhat joint decisionmaking process for delivery care, as an OF prevention method. When primary decision-makers are husbandswho balance spending of limited resources on one or more wives and children-male dominance can impede access to repair care. Although most women described decisions for OF repair care by a husband or a family member (parents, grandmother, sibling, uncle, or children), few describe making the decision on their own; women who did tend to have temporary jobs or were abandoned. This finding echoed throughout FGDs and IDIs. Within a household, women's domestic responsibilities prioritize others' needs and result in further delays in repair. In some cases, domestic violence poses an underlying challenge that limits women's care seeking agency.

A related, gendered concern in FGDs suggests a community perception that OF may result from promiscuity and perpetuates the shunning of women with OF, thereby further delaying their access to care. Beliefs in churches, mosques, or prayers about medical care, associations of witchcraft, and the preference of traditional healers as a first source of care often culturally impede women's direct travel to a health facility. Regional language and ethnic differences also emerged as challenges for those traveling long distances for repair-particularly if women 'fear' going to a new area, as described by those traveling from northern Uganda to Masaka. 
The co-mingling of norms around illiteracy, low education, early marriage, and pregnancy as predisposing certain women to develop OF and be less likely to access repair care drew consensus across community, provider, and district management perspectives. Dropping out of school early and in conjunction with early pregnancy (e.g. provider describes fistula patients she sees are often under 18 years) increases risk. Additionally, given the cultural taboo to have children out of wedlock, younger women often hide their pregnancies, which perpetuates a cycle of limited access to antenatal, delivery, and postnatal care.

"My husband and my mum [made decision to seek care]. It took a month."

IDI, client living with fistula, Hoima

"There are times when you don't have money as a man and the lady is sick so you make her to get herbs instead of wasting the 5000 ...This causes the situation to become worse for the women."

FGD, community men, Masaka

"People don't like to associate with them (babekokola)... my studies ended from there when I got fistula.

Even the stall that I had was closed because I couldn't touch anything and someone would eat it."

IDI, post-repair client, Masaka

"Our Rwandese practice where you are grabbed and forced into marriage...So I ran away from there but I hadn't known that I had come with a pregnancy...the relatives treat us badly because my mom who was there for me died after one week of my first repair. I stayed with my big sister who treated me so badly...she gave me a hoe to dig that no one cares about you anyway. You don't have legs but you have to fetch water and do all the home chores....When we came here in Uganda I ran away from her."

FGD, post-repair client, Masaka

"Some of them are even prevented by their husbands that they should not leave them at home they have responsibilities caring for their children something like that."

IDI, fistula surgeon, Masaka

"...Makes women to be treated badly when the husband hears that his wife is dated by some else or sleeps elsewhere not home. Or when he goes to fetch firewood, someone goes to his home and sleeps with the wife-so when the wife gets that sickness, he treats her badly. He cannot believe that pregnancy is the cause of that disease.... He can think it has been brought about by sleeping around with other men."

FGD, community men, Masaka

"The problem is the young girls are becoming pregnant...they don't take the responsibility...you find the parents also are not taking responsibility on their children by telling them to go to the hospital. So these children cannot deliver from the hospital they deliver from home because they are scared going to the hospital. They did not go there while they are pregnant so they end up getting that problem of fistula."

FGD, community men, Masaka

\section{Enablers}

Given the range of cultural barriers described, communities and providers utilize different mechanisms for shifting cultural norms on a range of issues-particularly gender norms-that empower women within their homes and facilitate reaching repair care.

It is important to determine ways of increasing women's decision-making power within their households: This translates, in part, to increasing a wife's financial resources through employment, which helps alter the gender norm that males control how money is handled. Many providers and community members (with and without OF) describe a need to encourage women's education, since basic literacy exposes them to information that may motivate care seeking at facilities for delivery and lowering risk of OF. In some cases, abandoned women who were educated but maintained financial resources were able to access and overcome traditional gender barriers. Increasing health literacy for RMNCH that emphasizes OF prevention and treatment should be developed and implemented. Involving community men is critical since, as noted, this group holds the decision-making power about birth facilities, and there exists a cultural obligation for a man to protect and take care of this family. 
Including spouses (and other accompanying family members) in post-repair counseling, educating boda riders or others that transport patients to and from villages, and conducting community-workshops (through VHTs and churches) were all described as ways to involve both men and women in shifting cultural attitudes toward women living with fistula.

In the facility setting, cultural enablers may require offering translation services so that repair procedures are understood and post-repair counseling and follow up are effective.

"Those who come just make their own decisions. For example, those in the municipality, most of them have been exposed, have gone through schools, at least they must have heard about advantages of coming to deliver from health facilities."

IDI, nurse-counselor, Hoima

"Before we were trained about it, I had never heard that even that fistula exists...the women who suffered from this health problem-they thought that they were bewitched especially those that have their co-wives...maybe they have just been quarrelling over land boundaries, she can just say that maybe such person is the one who bewitched me so I may leave this home. And they keep going to witch doctors, and even at times fire back to that person and yet that person has nothing to do with it...they lack being educated." FGD, community women, Hoima

"When you have that problem, you don't have appetite in your entire life...now with such a problem maybe like those stay without treating themselves...if you are like an intolerant woman you may even separate with the man and you feel restless in your daily life and even you don't associate freely. You feel something is lacking in your body. Now like me am a business woman, whenever I am going somewhere, I have to pack something, in case the problem finds you there, you can then pad yourself." IDI, client awaiting repair, Hoima

"I don't blame...women, it is the responsibility of the man to treat his wife. A normal person should... treat and care for his wife; those who are bad-their children fear them and run away. All men should create time with their wives so that they share the challenges now like this fistula, the men should be involved a lot. For those who live nearby the hospital, can be easy, sit on the boda. But us who come from far ends...it is the role of the man to mind his wife and care for her treatment...Let women tell their husbands early, and if they neglect them, let them listen carefully on the radios...about the hospitals and...how they can reach there. I saw an old woman here with her daughter who didn't have transport or knew the way back; the hospital vehicle helped drop them." IDI, spouse, Masaka

"The nurses were happy but because I don't know Luganda-even when somebody is happy for you, you cannot speak with them, people don't like Lusoga." IDI, client awaiting repair, Masaka

\section{Social factors}

\section{Barriers}

Social barriers to repair care are paramount for women affected by OF, often stigmatized, isolated (to varying degrees), and embarrassed to ask for help, both informally and from the health care system. Negative reactions of husbands, immediate and extended family members, and the community present social barriers that not merely exhibit a lack of adequate support, but often actively deter women from seeking repair care. Negative reactions cited include a husband or family member "chases away," "treats badly," "abandons," or "abuses" a woman with OF. This causes women to remain silent about their condition, while coping with the challenges of managing it (cleaning herself, her bed, anywhere she goes). Community indifference, gossip, and dismissive practices (pointing fingers, calling women 'smelly') limit women's ability to engage socially or participate in routine activities (going to the market). Women's disability and discouragement from social activity normalizes the culture of silence around OF. Many women live in insolation in their homes or places "away from the public." 
Although often women's groups or social networks act as enabling factors toward care, information shared through them may inhibit access if the information is incorrect or perpetuates misconceptions about facilitybased services (maternity and repair care). In few instances, parents who sought advice from friends about how to 'fix' a daughter living with fistula repeatedly heard that the disease is not curable at a hospital-based on anecdote or belief in witchcraft. Social support by family members can decline, as seen from situations where financial and other barriers interact and influence social relationships around women affected by OF.

"What they know in villages is all about people talking about you nonsense how you have fistula and you don't seem to get any help from them. Even when there is a community function like a wedding and you would like to go to attend; they would talk about you and point fingers in you so you end up stressed and go back home and sit alone." IDI, client awaiting repair, Masaka

"You don't have peace among your friends and you don't relate freely." IDI, client living with fistula, Masaka

"Neglect and stigma...It begins from homes-your friend can come to help you during postnatal session but after a while they see you with fistula so they may end up dumping you and go on their own. This also may follow the rest." FGD, community women, Masaka (8)

"It begins from the bedroom when your hubby may even stigmatize you."

FGD, community women, Masaka (3)

“They are mistreated. If you're a woman you face a lot of trauma, the man can leave you alone. If the man sees that you keep leaking urine, the man starts abandoning you for another woman who is beautiful, fine and does not leak. As for you the man dumps you." IDI, post-repair client, Hoima

"They get disgusted of you; your husband gets disgusted of you, the community members once they get to know, they get disgusted of you and say you smell for them, you're leaking...Even [family members]it's the same, as they gossip around." IDI, client living with fistula, Hoima

"There are women groups that they share their issues with instead of going to hospitals they choose to share with friends who don't even advise each other appropriately. They would have gone to hospital instead but the friend ends up discouraging each other." FGD, community men, Masaka

\section{Enablers}

Despite the number of social barriers, all participants noted important role played by social enablers in getting women access to both delivery care (prevent OF) and repair care. The support by husbands and male relatives was integral to reaching care-whether this involved decision-making, financing, or accompanying women to facilities where repair camps are held. Husbands, mothers, sisters, grandmother (strong elder woman) were often described by women suffering from fistula as well as others in the community, as key social enablers in terms of condition management in the home (buying soap, pads, other material needs) and accompanying women to care. There is cross-perspective agreement around the notion that irrespective of how a woman is treated by the community and broader family, if she has the support of a few individuals who truly sympathize and are determined to help, she is more likely to make it through the first two delays (Thaddeus and Maine) and reach a facility for care (the majority of clients are accompanied by someone.) Once at the facility, these accompanying family members serve as advocates for fistula clients in that they are able to provide ancillary care, talk to providers, monitor healing (during camp and post-repair), and communicate to hospital staff when a woman's needs are not being met.

Community sympathy, support and sharing of knowledge of treatment options and schedules (camps are every 3 months) also emerged as important for all women, particularly those lacking familial support (i.e. abandoned). For some women, community liaisons (members of VHTs, the 'good Samaritan') for knowledge, transportation, and accompaniment facilitated access to care. Outreach and advertising for camps in community settings 
(churches, mosques, dramas) likely began to reduce stigma toward the condition. Women's groups, community identification, and discussions at camps represent collective social support mechanisms that may either facilitate access (financial/information sharing) or emotional support (that one is not suffering alone). How much community support a woman gets may depend on how that woman is perceived by her community.

"For me my husband took good care of me, in the morning he would get the bedsheets and wash them." FGD, post-repair client, Hoima (1)

"For me my husband it does not affect him because we stay together...when he heard the announcements over the radio, he said we should come." FGD, post-repair client, Hoima (8)

"Even my maternal relatives know, in fact many people now know about it...they treated me well, they didn't segregate me at all. In fact they took care of me." IDI, post-repair client, Hoima

"People ignore you-they don't want to sit with or near you...The husband isolates you because you can't even sleep or have sex with him, but my mum can't isolate or ignore me like others."

$I D I$, client awaiting repair, Hoima

"She gets very shy that she cannot even talk and tell someone...if I had not put in effort, I would not knowshe would have kept quiet. But because I was close, I would check and ask her why the bed sheets were looking funny...A woman also calculates when she doesn't have money and she asks where do I begin, when you hear Kitovu, it is so far from Kiboga....because I wanted my granddaughter to be fine I decided that nothing will stop me. But other people really lack money and capacity and they fear and stay lonely."

IDI, grandmother, Masaka

"They [client living with fistula] have to come to the hospital; they can be repaired. I know of many and they are there fearing to come here...when I go back home I am going to tell them to come...I was requesting doctors to treat my mother to be like other people...they also become normal." IDI, daughter, Hoima

"I don't think that challenges preventing people from going to the health facility are there. If the person does not have money, he/she can approach the VHT for assistance....I [VHT] would sacrifice to assist those who cannot afford...I feel empathy and tell her that if you don't have someone to escort you, let me escort you, I will assist you and be together in the facility for all the days you will spend there."

FGD, community women, Hoima

"Few social groups within the community help identity the patients but largely through radio announcements and maybe through churches, mosques help to tell patients to come for fistula care."

IDI, fistula surgeon, Hoima

"It depends on how you the fistula woman treat yourself. If you are abusive they will neglect you as a smelly woman but if you are a good woman they will also sympathize with you and help you when in need."

FGD, community men, Masaka (1)

"The community people are challenging once they know you have HIV or fistula."

FGD, community men, Masaka (2)

\section{Financial factors}

\section{Barriers}

Financial barriers such as generalized poverty, inability to pay repair expenses, and women's limited capacities for non-physical labor jobs restrict and delay their access of repair care. The concentration of women suffering from OF living in poverty speaks to an inability to prioritize fistula treatment (given it is not life threatening) over other household expenses. Moreover, managing one's OF condition (on own or within a household) requires financial resources to purchase materials like soap, clean sheets, and pads-all of which depletes household earnings and particularly burdens low income families and abandoned women. A woman's inability to work 
places strain on herself and others in the household to manage limited resources-which at times results in further impoverishment and isolation. Providers see clients' poverty status, lack of transport, and lack of husband support/accompaniment, and 'ignorance' as intersecting barriers to repair.

The prospect of paying anywhere from just under 10,000 , to 650,000 , shillings ( $\$ 3$ to $\$ 190$ ) over the course of reaching and receiving repair care at facilities delays care seeking for days to years. Women, spouses, family members, and providers describe cost as deterrent: Money is often needed for transportation (to and from), facility stay (e.g. food, tea, soap, medication), and to a lesser extent, bribes to hasten the process and reduce waits. Communities describe borrowing money, selling goods (goats, crops, land) for sufficient finances as a part of decision-making for seeking OF treatment. Providers do not explicitly acknowledge bribes (although they describe corruption as broad problem in health facilities), but confirmed that insufficient fistula camp funds (particularly in Hoima) pose financial strains on families, since most women are not refunded for transportation nor are they (as well as accompanying family members) given food and other provisions during their facility stay.

"They are many...many people...suffering...in the villages because of poverty...people are poor...I am also doing very badly...this chest hurts but I go there and they tell me they are ulcers...yet I have to maneuver. What will I do for the children to study, and I also think with a lot of misery because these ones, their mother died. Now there is another one who also left me with orphans. I encounter a lot of suffering because I see the orphans, and yet I see mine [daughter with OF] suffering." IDI, family member, Hoima

"You may find a woman....with no money at home because you, as a man earn little, so you leave little...Some stay very far deep in villages...You find a person has to pay 30,000 [\$8.77 on a health center, so one may choose to stay at home because of that." FGD, community men, Masaka

"It has several effects, on especially the girls and women...once a woman gets fistula, in most cases-if she was married she can't remain, she has to divorce...she can't really be progressive economically because she can't work with that problem...She is always smelly so this one prevents from maybe doing her business and associating with other people even in the community. So it becomes very difficult for her to continue living socially in the community."

IDI, district level manager, Masaka

"It was some time, it was like two years, and all this time we knew it would be treated but we didn't have the money. Most times what makes these people to remain in the villages is lack of money...You know right from back then money has been a problem, and we could even sell some things. Anybody who has money finds it easy to come to hospital and for those who don't...remain in the villages-that is why you hear that some people went to TBAs who you can give, like, ten thousand shillings and they help them deliver, but even when you know that they are not doctors, you have nothing to do." IDI, spouse, Masaka

"These women are poor and some of the facilities...they want money...the health facility doctor, to work upon you, will tell you that you give me at least five hundred thousand and yet you do not have moneythat is it, corruption among the medical workers has become rampant." IDI, nurse-counselor, Masaka

"Most of our fistula women are poor, you can count on hand the number of people who have any kind of insurance nor anything, and as for a bank account, they cannot sustain them. I can say, ohm, yes that poverty is the big thing the big $\mathrm{P}$, poverty...the poverty and lack of education." IDI, fistula surgeon, Masaka

\section{Enablers}

Financial support is critical to accessing fistula care. Since fistula treatment in Uganda is free, women and families require financial enablers in the form transportation refunds or vouchers that could be distributed by camp organizers, NGOs, or government partners, to aid access to care. In cases where refunds were given and ancillary needs (food, water, pads) met during stay at the facility (more frequently in Masaka than Hoima), there was increased motivation to seek care. A key issue that emerged, however, is the need for collecting and saving money before initial transportation to a repair facility-particularly given the fact that the fistula camp was not always the first source of care. Often women were first accompanied to closer health facilities and subsequently referred. In addition to drawing on household savings, cashing in on assets, and borrowing (or accepting money 
as a gift) from family members, women and men spoke about pooled community funds that could be mobilized (via mobile money transfer) as needed (e.g. OF repair). In some cases, these types of loans were paid back based on appraisals of property, while in other cases, they involved more of continued socio-financial commitment as in the case of women's savings groups.

Additionally, women in FGDs and IDIs, as well as providers, described financial enablers as providing economic or job support for women living with and recovering from OF. Vocational training such as knitting, crafts, beadwork, weaving, and low energy trades that could be sold can help women generate income while not straining themselves during surgical recovery. Several providers felt that working with community health workers to help with post-repair counseling and job education would be particularly useful in healing, reintegration, increased productivity, and self-esteem for women recovering from OF.

“As for money we did not have, we didn't have money only that when we heard, the announcement itself said that those that are leaking urine and feces you should all come and do what, and get treatment, there is free treatment and also come with the person to keep you, a caretaker and also them their money is paid for and also the transport that brought them will be refunded. We shall feed them and also the treatment is free. So this forced us to come." IDI, family member, Hoima

"My husband paid for our transport we had grown beans which we sold and later got money...we first paid off all the debts which we had so we used the little balance to come here. After this little money got finished we again started borrowing from friends and that's how we are surviving."

$I D I$, client awaiting repair, Hoima

"It was our neighbors [who decided]...the community...The elders, my brothers usually in our village-it's these who help in taking decision...I had some money but it wasn't enough so the community collected for me money to come for treatment...The problem I have-this isn't my money, it's community money... its costing the community... when I need any money, I call my community members and they send me money via mobile money. I am going to pay it after-they will value my property and then I can pay."

IDI, spouse, Hoima

"I think if they had women groups at the village levels and these people are funded. Because like individually you find some are unable to stand on their own and do anything that will benefit them but if it is a group then they benefit."

IDI, ANC/maternity staff, Hoima

"Regarding finance, we need the money, may be they can teach us things like vocational skills, now, like me, they told me I can no longer lift heavy things, but yet I need the money."

IDI, post-repair client, Masaka

\section{Transportation factors}

\section{Barriers}

Distance, cost, and difficulty of travel pose barriers to repair care access and comprise the "second delay." Participants described women seeking fistula care traveling from near and far-all around the country as well as from Rwanda and Tanzania. Women and their companions traveled from Masindi, Kihemba, and Kyannati to Hoima Regional Referral Hospital, and from Jinja, Tororo, Iganga, and the northern regions to Kituvo Mission Hospital in Masaka for repair. While some of these districts fall in the catchment areas of facilities in which Fistula Care Plus is active (in Masindi), others do not. Additionally, many travel extensively from 'deep villages', 'in the forest', or other remote locations and are dependent on companions for support en route.

Providers and clients concur that travel often involves multiple modes of transportation and hours to reach camps, on foot, boda, bus, taxi, or vans, over various terrains. The variability of transportation and distances lead to a range of associated expenses, with those living closer more likely financially able to reach care, while those farther away may need greater financial enablers to sustain both a woman and accompanying family member 
(typically at least one) during the journey. One concern that came up was the security for women seeking repair care alone (or with someone they don't know). Another transport barrier revolves around the cumbersome nature of fistula management while en route-some community members describe the smell emitted by women with OF as making transport operators or other passengers uneasy. The prospect of or actual public rejection of women with OF delays, halts, and prevents altogether care seeking.

"Transport is also a problem. All the villages we come from are very far, even me from home to here it is 30,000 shilling. From home to the main road on a boda boda we spend 10,000 shilling just two people. From the main road to here, it the vehicle cost us 10,000 shillings each. Now you find that some don't have any means of transport to access where treatment is being offered." IDI, spouse, Hoima

“Now where we stay in the village we don't have any means of transport to get us quickly to where we can access the main road where the cars are. The roads where we come from are not good, now sometimes you get a boda to take her to the main road and yet the roads are bad sometimes muddy with potholes and they are serious."

IDI, spouse, Hoima

"The women will fear to pass in public because people will tell her she is smelly. The boda people or taxis will refuse them in their means so they will go back home and sit." FGD, community men, Masaka

"It took long for me because from the village to the tarmac road it was very hard I footed and reached when I was wet allover. I couldn't sit in the car very well - I sat in the taxi and I wet the seat and the conductor chased me out of his vehicle."

FGD, post-repair client, Masaka (1)

"There is a boda guy who rode me from Kawaala to Masanafu and I sat on his boda from church I wet all his seat and he quarreled with my sister that never allow you sister to sit on boda again."

FGD, post-repair client, Masaka (6)

\section{Enablers}

There is a need to improve transportation and reduce costs for women seeking repair care at camps (or routine care centers). Communities and providers concurred on the importance of covering costs to and from repair facilities for women and, if feasible, a companion (as most women do not travel alone). Transportation can comprise various forms, strengthened by improved referrals and ambulance capacities at health centers, which would combat OF by reducing prolonged labor. While some accounts of boda bodas and taxis were negative, others portray these operators as supportive and non-discriminatory toward those with OF; in some cases, nurses describe counseling boda riders transporting women after repair on driving cautiously, educating them briefly on OF and the critical nature of the woman's condition. Nurse outreach (or other liaisons such as VHTs), via taxi, bus, or van and cell phones, can help identify and bring OF patients from distant villages to repair camps. 
"Some bodas are kind hearted they can take you for free if you tell him your problems I saw one who did that to a person."

"They should help them because they are many who have remained sick because of lack of money they cannot come."

FGD, post-repair client, Hoima (2)

"We are asking they provide us with transport to bring us here."

FGD, post-repair client, Hoima (3)

"For me I want treatment and transport to take me back."

FGD, post-repair client, Hoima (4)

"They should help us and give us transport because we can be when we have just sacrificed to come and even transport to take us back we can be when we don't have it."

FGD, post-repair client, Hoima (5)

In unison "It [smell] doesn't [matter]."

FGD, community women, Masaka

"No it doesn't affect them because the boda people are making money and they don't have to stay with them for a very long time."

FGD, community women, Masaka (1)

"If we know we now have ten patients, we go and screen them. After screening them we get a [passenger service van], put them in, and bring them to the center. Or we have some places where we know the buses so we tell the patients to board those buses and they find us on welcome [Nyendo Masaka-Mbarara junction] and then we pay the buses and get our patients so that is how we are dealing with it. Also we use phones to call them and handle them to the nurses in the nearby health centers and then those nurses take the responsibility to put them in the taxi and buses and then give them to us."

IDI, fistula surgeon, Masaka

"Now if it's in the church, who goes in the church can here that announcement then the parish priests can send it to the lower levels so that every Sunday its announced and however hears we usually tell that they can gather around the church or on the health center if there are there we put on our telephone numbers then they can ring to us that in such an area we have these patients how can they come to Kitovu majority they are poor they don't have transport the good thing is that lets say they are on a health center, once they ring to us we can send our van to collect those patient."

IDI, head matron, Masaka

\section{Facility shortage factors}

Facility shortages in both human and material resources represent barriers accessing adequate care once a woman and her companion arrive at a fistula camp. Fistula repair care not only requires adequate numbers of specialized health personnel such as surgeons to examine and treat various levels of tearing, but also a supportive nurse-counseling staff to counsel patients before and after repair. Recovery takes longer than for other surgeries, requiring long hospitalization and follow up services. At Mulago Hospital in Kampala, where routine care is available, women are rarely treated for fistula given its low priority and generally high patient load for surgical and medical procedures. At fistula camps in Hoima and Masaka, shortages are attributed to surgeons being too busy, "the doctors had gone," or lack of sufficient funds for food and hygiene products for women preand post operation, as well as transportation costs. These shortages have direct implications for quality of care (discussed in the next section). Staff shortages are likely associated with demand and supply factors such as high patient load and salary structures for the health care staff. The exhaustion of fistula funds during camps results from the lack of clarity about the burden of fistula in the country and the resultant inaccurate projections of expected clients. Sometimes medications were unavailable and although material resources for surgical procedures were generally problematic during camps, matrons dealt with shortages by appealing to private financiers in their networks. 
"The burden of fistula in this district is big. I don't have figures, and mainly because most of the mothers who get this condition, they don't report to the hospital. You find some deliver with traditional birth attendants and some deliver in the hospitals, and if they go back they don't come back to hospitals, so it may be difficult to know the exact numbers... who really have obstetric fistula, but what I know it's big, because from the recent camps we have had in the district-we have had around four to five camps-but the first camp our target was 40 ...we were wondering how we were going to get all those mothers, but when we went to air and we talked about fistula, we described what a fistula is and we are going to have a camp, we got $\mathbf{2 0 0}$ to $\mathbf{3 0 0}$ mothers in this district, and other districts, so...the burden is high."

$I D I$, district level manager, Hoima

"Most hospitals here are government hospitals and when you go, the health workers may tell you there are no drugs and may send you to buy from the clinics."

FGD, community men, Masaka (4)

"You may go to Mulago hospital with your wife and you endeavor to be early enough but because of corruption the person who has just come may pass you from the queue and is attended to first. So you may be very hungry and annoyed so you end up going back home with hopes of coming tomorrow again." FGD, community men, Masaka (2)

"Others lose hope and don't even come to hospital at all. So they look for other alternatives once they fall out with health workers. Also health workers around our health centers here are very few. You find them overwhelmed and really tired remember they get very little money as salary so they end up frustrated and replying you any how they wish."

FGD, community men, Masaka (1)

"I think the health workers here are few as patients keep complaining that they have not reached me and me like that. Sometimes they reach them but the workers are very busy, also the patients who come here lack patience...[laughter]." FGD, post-repair client, Masaka (4)

"You find they have to do it all wash for those who have no care givers, remove the catheter, administer the enema, is on forms, check those who is going to be repaired among other. If there is anything you can do for them please help because they become overwhelmed." FGD, post-repair client, Masaka (5)

"Imagine even the cooks who prepare all that food the last camp they registered 120 patients plus their caretakers. And some families are very generous they bring like two caretakers and they are all taken care of. [Nurses] cook breakfast porridge, lunch and super and in the end such a person is given less than 100 US dollars. That is unjust."

IDI, nurse-counselor Masaka

"Money for someone to participate [provider] in such a camp they need allowances because to do the daily and add on the camp work its hectic for example we worked all weekend so if you to have everyone working you need to give them an allowance so it needs money." IDI, nurse-counselor, Hoima

"These extra ones are not covered...then our director has to look for [money] somewhere...from other friends...we have Afrikara then these Fistula Foundation things of that, so they can support like now we have doctors in UK from the Royal College so they are also supporting where there is need."

IDI, head matron, Masaka

\section{Quality of Care factors}

\section{Barriers}

Closely associated with facility shortages, quality of care, as a barrier, manifests in delayed decisions for seeking care (quality of delivery experience), travels to camps (quality of referral systems), and fistula repair care itself (both amount of time and nature of experience). Disrespect and abuse (physical, verbal, neglect) by nurses during facility-based childbirth may lead women to seek traditional alternatives or to wait, sometimes weeks, before deciding to seek OF repair at any hospital. Many participants described negligent, prolonged labor and delivery experiences leading to stillbirths, which manifest in perceptions of poor quality and unresponsive care. Many women deliver at lower level centers and are thus dependent upon inadequate referral systems 
lengthening their time and efforts for reaching repair camps (typically by few weeks or months, though sometimes years). The delays between provider assessments of urinary incontinence, foot drop, various drugs, tearing severity, and sometimes irreparable conditions represent referral system challenges complicating women's access to the right care.

Quality of care at camps reflects processes, waits, exposures and environment, and to a lesser extent, concerns around interpersonal quality (disrespect and abuse). Typically, at camps that last about two weeks, women are registered fairly quickly (within hours), but wait around two days (with a range of a day to a month) to be examined by the doctor, after which they continue waiting for their surgery. During these waits, participants (women, family members, providers) describe the individuals accompanying and staying with clients as caregivers, ensuring adequate nutrition and maintaining hygiene-at their own expense (Masaka camps have higher capacity for facility provision of food than Hoima). Participants also describe fear and actual contraction of other diseases while waiting for care at these facilities, given the exposure to infections in a limited space. In hospitals offering routine care, corruption discriminates against the poor, in terms of who gets more timely repair, as the poor often wait longer than those with money. Due to unanticipated shortages, some women are unable to be repaired according to scheduling. Language limitations and insufficient follow up care also appear to be problematic, particularly from provider and district management perspectives.

"They have bad attitude towards midwives [for delivery]. They think midwives are harsh, they think midwives ask for money. They are ignorant about services given in hospitals-they think they cannot be cared for." IDI, nurse-counselor, Hoima

"I pushed and tried my level best because even my eyes got swollen and I could no longer continue. [Providers] kept telling me to walk around so that the child could come out. They made me walk around with the child half way out but I could no longer continue, then the nurse barked at me and after wards they told my husband and mother in-law that I should be taken to Iganga, they could no longer manage me...but they [husband family]said that they didn't have money...my own parents are far from us and so I could not get any help, so I remained there, I almost died...in the hospital, the doctor did not even comfort me [after baby's death] or telling me that [OF] is serious, he just kept quiet and he just discharged us."

$I D I$, client awaiting repair, Masaka

"I have spent about three days here but they haven't worked on me...My sister is taking care of me. [Staff] welcomed us well-they assured us that there is treatment here we shouldn't fear anything, but they haven't given me any treatment...but the nurse was good." IDI, client awaiting repair, Hoima

\section{Enablers}

Participants shared recommendations, drawing on their professional expertise or personal experience, to improve quality of care and address facility shortages. There is a need to ensure adequate funding (via donors, government, private foundations, etc.) for fistula camps and increase camp frequency, as well as develop more permanent fistula-specific centers or designate areas within facilities to routinely treat patients. Specific wards or centers would be useful given the logistics around the continuous care required by OF patients who often stay longer than other inpatients. In addition to increasing funding, there is also space for strengthening oversight by working with partner organizations to reduce corruption and ensure coverage of repairs. Increased funding ought to not only support human resources but also pay for transport and ancillary care for women and accompanying caregivers (e.g. food).

Integrating care and post-operative counseling for cesarean sections and fistula repair are critical for adequate quality fistula care; this includes maintaining contact with fistula care providers or sufficiently trained nurses at local health centers near women's residences. Providers, in particular, feel this is critical. Providers and communities alike described the need for counseling and education on the return to sexual activity, nutrition, exercises for pelvic strengthening, co-morbidities, FP, the importance of future cesarean births, and follow up 
care. Participants unanimously felt the importance of encouraging women to return to normal life. This care improvement strategy requires better coordination with surgical teams, hospitals offering OF treatments, VHTs, and referring health centers. It also demands increasing provider awareness of screening and how to communicate effectively with patients about fistula (nurses, doctors, surgeons) through continued medical education seminars (CMEs).

"When they come here we must provide them with food, soap the beadings...bed sheets and so the blankets."

IDI, nurse-counselor, Masaka

"I am even just praising this hospital to even give us food, because everywhere we go we just buy food, but these ones give lunch and supper."

$I D I$, grandmother, Masaka

"We do not admit them in routine care, though we plan to start it. At the moment I have a lot of other duties that I do, I have emergency care, and other surgical problems that I have to deal with. So I intended to have them scheduled to be worked on like in camps other than taking them for routine. Though I hope that in future when I can get more staffs, I may have to dedicate some time for them."

IDI, fistula surgeon, Hoima

"Even...a building that is special or a hospital that is special for that sickness, that becomes easy for people to say that that hospital is for people who leak urine and feces-that becomes easy for her to go direct. She goes knowing that everyone I find there is like me...so they don't look at it in a bad way....our hospitals here, since we have no services for fistula here, they get a room special or get a day-say Wednesday-we shall be treating women with such a disease and the drugs are there you...it known to them that it's a special day for treating such a sickness. So if there is anyone with that sickness-when they miss this Wednesday then the next one they have come and get treatment."

FGD, community men, Hoima

"That is holistic care-the care that we giving them includes all the physiological social, physical."

$I D I$, nurse-counselor, Masaka

"Normally, on discharge we tell them, first of all we tell them hygiene is very important, and therefore they should maintain hygiene, and also they should abstain from sex, like, three months, and we also tell them to eat a nutritious diet, and we also tell them, like those childbearing mothers, don't to get pregnant like for one year, or sometimes they go with family planning methods...in case they conceive they should not deliver at home, it should be in the hospital under cesarean section and to attend antenatal care."

IDI, nurse-counselor, Hoima

"Have the technical people like the anesthetic assistants recruited and the theatre assistants and then we need also to orient or train or orient the medical officers at health centers. Thirdly our midwives also handling those issues have to be oriented and then improve on the supplies."

IDI, district level manager, Masaka

\section{Policy and political environment factors}

\section{Barriers}

Policy and the political environment affects how fistula care is structured, funded, and delivered in Uganda. The greatest barriers revolve around financing and implementation of policy plans reflecting a complex donor funded and locally supplemented OF repair mechanism, lack of effective targeting for community mobilization and lower level health center training, and generalized poverty in the country. Barriers to effective implementation also stem from the fact multiple groups (social, medical, transportation) must coordinate to address these multiple layers of barriers to care. Given the financial constraints families face in healthcare seeking and the low priority of maternal morbidities such as fistula, the general public expresses degrees of indifference towards the condition. 
"I think poverty as the former has said is problematic, really people suffer from health centers but there are no drugs. They come from far ends to Mulago knowing that everything there is free when they reach it isn't true you have to pay...Other hospitals don't work on fistula and refer them to other hospitals. I wish it would be put in most health centers that will help people a lot."

FGD, community men, Masaka

"The Government has put up services but people still have that attitude of how does it concern me...that is what is causing a problem."

FGD, community women, Masaka

"At the district we have no ambulances...the human resources have tried to address, but we lack enough qualified staff at the facility...much as we at 70 percent...the health system, in terms of transport, that is still lacking, maybe the health workers need some training...much as they have some information about fistula, they need some training and also we also need to sensitize our communities about this."

IDI, district level manager, Hoima

\section{Enablers}

The existence of a National Obstetric Fistula Strategy (NOFS 2011/2012-2015/2016) is a starting point for facilitating repair access; however, it requires more financial commitment to effectively target vulnerable women and transport them to adequate care and follow up, as well as better understanding causes and treatment. Many nurses and surgeons described OF treatment as a team effort involving collaborative practice and adequate training; building such capacity at repair facilities, referring health centers, or other referral bodies, and broadly, in the community, is a key policy enabler. A focus on training for health centers that are often understaffed (only 1 to 2 midwives-nurses) is critical because these are often the first points of contact for many women suffering from OF. Women suffering from OF should be treated like other persons with disabilities described in the Health Sector Strategic Plan III (HSSP 2010/2011-2014/2015), given their inability to work and limited access to timely care, in the current landscape. Moreover, institutionalizing vocation skills training as a part of repair follow up, to facilitate rehabilitation and reintegration, is important for all women recovering from OF, and particularly those with no husband or family support.

"We need more money for community mobilization because that can help a lot to prevent fistula...people are ignorant about that fistula problem, they should know and the only how we have to tell them that there is such and such a problem we have to go deep in the villages and tell them, teach them."

$I D I$, nurse-counselor, Masaka

"We still have a long way to go...we, as fistula surgeons, should not be convinced that we have reached the climax of management of fistula; we are still starting we have to know that fistula repair is a team work. We have to involve everybody in this process; bringing the patients here-we need to involve ourselves in that. We also need to involve the whole country at large the social, the religious, the local leaders-everybody has to be involved...many people are still illiterate on fistula, so we still need to continue with education in the communities and also we use the radios televisions and talk as much as possible about fistula to help prevent the barriers." IDI, fistula surgeon, Masaka

"For district service providers, they should give us support like they help [people with disabilities] because we are also unable to do work, that is also a disability and so we need support...We also need financial support especially when our husbands do not care about us, we need to survive." IDI, client awaiting repair, Masaka 


\section{Healing and reintegration factors}

\section{Barriers}

Participants frequently described healing and reintegration as a factor that affects repair access for both themselves and others in the community. Barriers to healing and reintegration relate to perceptions of repair operation, experiences during repair camps (or having experienced multiple repair operations), and postoperative social dynamics and health care interactions. Repair outcomes (success, failure, multiple operations) and follow up care determines how reliable operations are, a woman's faith in the repair process, and whether or not she's willing to seek care. The longer women wait to be repaired and greater the number of repair attempts, the greater the skepticism around repair efficacy-this is further complicated the type and nature of tear, as well as the ability of providers to conduct repairs. Additionally, quality-related measures around women's experiences while at camps may affect healing. Recovery from repair (and the prevention of new tears) takes a longer time than cesarean section-which poses challenge to successful healing, which demands restraining sexual activity and physical labor, while maintaining good nutrition and adequate follow up care. Though providers often see relapses as resulting from women's "not following instructions," gender dynamics of households suggest that women may not always have the power to control when she engages in sexual activity.

"If one comes and they are operated and didn't heal, they may discourage others that went there but didn't heal." IDI, nurse-counselor, Hoima

"They have stigma...how do I go there, they imagine how are we [providers] going to receive them and other, but mainly stigma. They are like, 'Will I heal since I had this problem for 10 years or $\mathbf{1 5}$ years?'”

$I D I$, nurse-counselor, Hoima

"They [clients living with fistula] can be repaired, but it is not a guarantee that you will be fixed like me I have been repaired for six times but up to now it has so far refused." IDI, client awaiting repair, Masaka

"Sometimes others come when they do not have attendants, and like the nurses cannot be there full time, you cannot offer the care the patient needs like taking the patient sometimes for bathing such things. Yours offer this treatment but other things like washing you may not be able to do it. And others are like they do not have, because attendants sometimes they come but sometimes they do not have food to eat. They expect the hospital to provide also for the attendant. So sometimes they attendants go way even for fistula because most of them will spent like two weeks others get tired along the way and they want to leave the patient alone. Sometimes it depresses the patient and may delay healing."

$$
\text { IDI, head matron, Hoima }
$$

"It is true that not all fistula repairs are successful, most of them that have been worked on here have been...but of course there some who have ended up failing...sometimes it is because some mothers have failed to follow up instructions...but others may fail just like an operation may not be successful."

$I D I$, nurse-counselor, Hoima

"If one begins sex too early it will break. And if one conceives too early also, it will also receive pressure and break or if one decides to deliver vaginally it will by no means just break."

IDI, ANC/maternity staff, Hoima

\section{Enablers}

Healing, or the promise of healing, appears to be motivational for women living with fistula, and is often related to repair care at facilities' outcomes and quality, especially 'holistic' care. Reintegration, however, builds on clinical healing opportunities and a woman's ability to return to her normal productive and social life. Reintegration is a more social and community health domain, necessitating communities' OF acceptance as a destigmatized condition. Enabling healing and reintegration both requires the treatment of women with OF more humanely, both in their communities and in health centers. It also can be achieved by fostering vocational skills, 
along with self-determination, and sense of social support through interactions with other women sharing the same struggles and repair process. As one of the exemplary quotes of a client awaiting repair illustrates, her confidence in healing from repair was not only built through an increase in knowledge about OF from her doctor, but also her interactions with other women at the camp who describe similar pathways to recovery. These types of positive peer-interactions and counseling sessions ought to continue as women return to their communities in order to foster a culture of healing and reintegration.

“These women should get good treatment from homes, they shouldn't be neglected or segregated or abandoned. That the first treatment-they deserve it helps them to reach the treatment they haven't yet received." FGD, community women, Masaka

"We have good care here-they even teach us how to do hand and craft so that we are not stressed. We leave theaters and you find the bed laid and is clean, nice cleaners and that boosts you to feel you will be ok...and they give you the transport back home. They give you porridge or tea, rice, or posho and beans for me I am happy here. They have not stigmatized us at all." IDI, client awaiting repair, Masaka

"The problem I found was not getting healed, I would such everywhere for treatment but I could not get, but when I reached here everyone says their problem, saying, 'For me I was operated four times, but I have not healed'...so I said, 'eee-even where I ran for help, there are also these kind of things.' But the doctors taught that others might think they will get healed yet they have several holes, so when you go for check up and they see another hole, they operate you again, that gave me confidence."

IDI, client awaiting repair, Masaka

"The counselors like after the operation are supposed to link them to community groups that aid them to go back to the community safely. Even then they are hare some groups usually come to offer support when they know if we have a camp, or some organization may come to offer support for the care."

IDI, head matron, Hoima 


\section{Discussion}

Barriers and enablers for access to OF repair and care are clustered around awareness, psychosocial, cultural, social, financial, transportation, facility shortage, quality of care, policy and political environment, and healing and reintegration factors. The findings of this study reinforce and add to the nine factor clusters identified in a systematic review of the literature (Bellows et al. 2015). Healing and reintegration emerge as a new domain in Uganda, suggesting that decisions related to access reflect whether or not women believe in the cost efficacy of repair, including a camp or facility's ability to deliver holistic care incorporating physical, sexual, psychosocial, and economic rehabilitation to "normal life." While women affected by OF, their families and communities, providers of care at camps, and their management concur on the range of factors affecting OF care access, the relative influence remains difficult to measure. The fact, however, that some women are uniquely positioned and knowledgeable about OF repair options (those who heard about camps on radios and promptly sought care), motivated (either internally or by spouses or other family members), with sufficient resources to cover travel and ancillary costs, is encouraging and suggests that certain barriers and enablers may exert stronger influence than others.

As seen in the quotes of our respondents, many determinants of care affect each other as well as the larger issue of access to repair in both direct and indirect ways. Related and cross-cutting barriers often involve poverty, early marriage and limited education, gender dynamics within households and communities, and women's agency for making choices about their reproductive health. The underlying poverty of women and their families limits financial access to quality repair care since frequently-particularly in Hoima-accompanying caregivers often bear the costs of ancillary care during the long hospital stays associated with waiting for repair and postoperative recovery. A married woman's limited power in her household impedes her agency for making care seeking decisions; the shame associated with OF is debilitating and often only overcome if a family member mitigates it with financial, psychosocial, and social support. The dynamics of women's agency and empowerment against (and within) socio-cultural norms of "leaking women" and implications about their sexuality, role in society, and surgical care seeking may vary by education and vocational statuses. These related and crosscutting factors amplify existing awareness and transportation barriers for those living in remote areas who are less exposed to radio communications that advertise camps and are dependent upon local referral mechanisms such as VHTs, local leaders, women's groups, and churches.

The importance of care quality and referral emerge as key in determining access-with respect to both prevention and treatment of fistula. While care quality at a camps are perceived as generally 'good' compared to routine provision of $\mathrm{RMNCH}$ care, logistical and financial challenges to providing adequate treatment often fall short given the high demand and overwhelmed facilities. Participants concur that often in routine settings, OF patients are neglected; increasing camp frequency and the development of OF-specialty centers render an amenable political environment for repair provision. Prevention of fistula through the promotion of skilled birth attendance through ANC and the reduction of disrespect and abuse during childbirth (D\&A) readily emerged from the data. Noted across perspectives was also the issue of provider knowledge and behavior at lower level health facilities that represent a first point of contact for women living with or at risk of developing fistula. The fact that many women were not told about their OF condition despite having delivered in a facility or were neglected during childbirth poses concern and have implications for increasing provider awareness around OF screening and referral as well as the promotion of respectful maternity care (RMC).

\section{Conceptual framework}

Figure 2 (following page) illustrates the theoretical process by which various factors lead to the overall reduction of women living with OF in a community to those able to access successful repair care from the formal health system. At the population or community level, where a certain proportion of Ugandan women suffer from fistula, 
awareness, psychosocial, cultural, and social factors influence their readiness and willingness to seek care, while finances and transportation affect their ability to do so. Most women first seek care at health centers, at which providers exhibit varying degrees of awareness about fistula screening and repair. The full range of demand side factors (awareness, psychosocial, cultural, social, financial, transportation) further influence whether a woman reaches an appropriate referral point for fistula care. Supply side factors, including facility shortages and quality of care, subsequently affect whether a client receives adequate care. At each stage there is notable attrition. The policy and political environments-of RMNCH, OF, and PWDs-in Uganda, funding commitments of the government, donors and other partners, and the structure and schedules of fistula camps determine how repairs are sought and received. The healing and reintegration of women with OF further influence both the attitudes and actions related to OF in communities.

Figure 2: Factors affecting fistula repair access

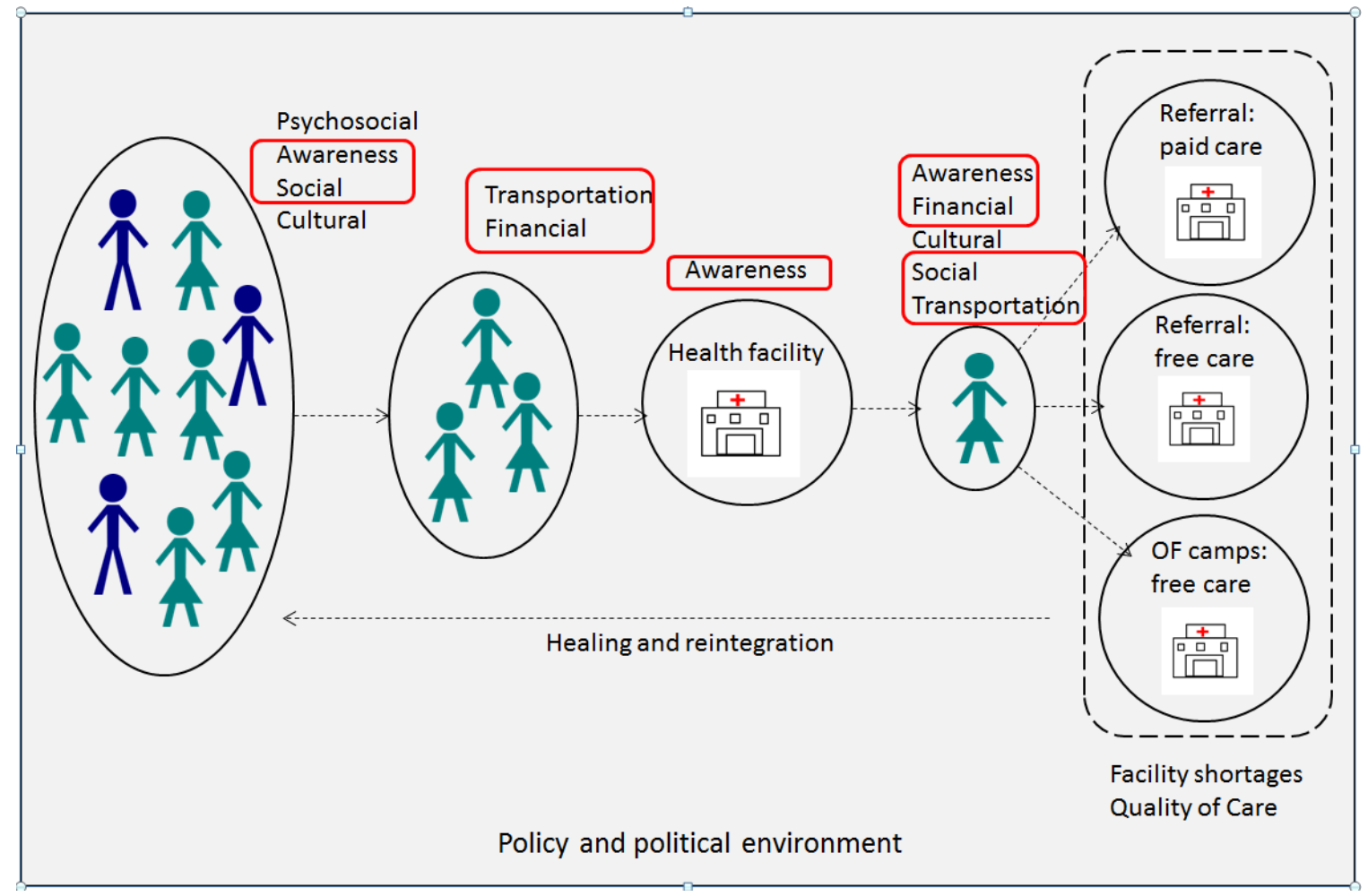

Given the range of barriers to repair access in Uganda and positive policy language for promoting awareness, social, financial and transportation support, the deliberative discussion of formative research findings suggest a need to focus in these areas (circled).

\section{Data limitations and future research}

This formative research provides a comprehensive mapping of the broad issues facing women living with fistula in Uganda, including knowledge, care landscape, and sociocultural and economic dimensions. Although this report reflects a scoping exercise-an inductive approach that draws upon the framing in systematic literature review and maintains goals of behavioral explication-the richness of the data warrants further analysis with additional theories of health behavior, gender, and health systems. Reflexive reading of the quality of transcripts shows that women's willingness to engage in group discussions may vary by region, setting, and timing (pre- or post repair). For example, an FGD with women after fistula repair in Hoima elicited less conversation than FGDs with community women in Masaka. 
There are still a number of areas that merit further explication. Having identified a range of barriers to OF repair access that appear fairly consistently in this Uganda sample, a diversification of methods can assess their relative influence on repair care access. Disaggregated analysis for each delay and overall time for repair would provide nuanced understanding of the care seeking process, with implications for programming and research. A barrier-enabler index would allow assessment of the relative influences of each barrier to care. In addition to women affected by fistula, male partners, family members, and surrounding communities are integral perspectives for monitoring shifts in socio-cultural norms-which apparently has started through Fistula Care Plus radio spots and $\mathrm{VHT}$ awareness activities. A barrier-enabler index coupled with quantitative and qualitative assessment of social norms, women's agency, and trust for repair camps would strengthen an understanding of each factor's importance. Given the limited scope of this formative research, findings about providers at lower level facilities warrant investigation. Exploring the experience of providers at lower level health facilities affecting both prevention and referral for treatment will provide a better understanding of the first and second delays of accessing care.

Formative findings suggest, in designing the next phases of implementation research, a need to collect data on socio-demographics, barriers and enablers, prevention, access to care, treatment prognosis, and reintegration to 'normal life' for OF. A conceptual model, starting with Figure 1 (page 2), that illustrates the problem, proposed solutions, and informing the study design, could be adopted. At present, we recommend a layered intervention at the community and (lower) health facility levels that reduces transportation, awareness, and financial barriers to accessing fistula preventative care, detection and treatment. The intervention would 1) develop and deploy a mobile screening and voucher-based referral system that promotes women's and communities' OF education, 2) develop and validate and index to assess respondent barriers and enablers to OF treatment, and 3) increase providers' abilities for screening and referring cases of fistula, as well as promoting respectful maternity care. To evaluate this intervention, a mixed methods approach is recommended, to strengthen the study's intervention development, implementation, and evaluation. The quantitative arm will draw on a screening algorithm and ascertain data on patients in the referral system over time. The qualitative arm (both IDIs and FGDs) will enable an understanding of the intervention's development, experience with the referral system, and further investigate healing and reintegration. FGDs, pre- and post intervention, will assess changes in attitudes about fistula that can be attributed to the awareness building activities surrounding the referral-voucher system, as well as its overall usability. 


\section{Recommendations for policy and practice}

- Adopt targeted approaches for addressing fistula, given the relatively small population that suffers from it as well as its 'identifiable' and stigmatized nature.

- Encourage referrals to fistula camps, centers of fistula excellence, or specified wards (at particular days and times) within general facilities, depending on which phase of institutionalizing repair services a country is in.

- Work towards developing centers of excellence for fistula repair and establishing regularly partitioned areas in regional hospitals for more effective, routine care.

- Increase and coordinate the timing of repair camps to maximize frequency across the country.

- Provide financial and transportation assistance to patients and accompanying family members.

- Integrate fistula into health education programming for youth, and in communities in general, through appropriate liaisons and in different sectors (such as education).

- Enhance fistula awareness in lower provider cadres

- Include women living with fistula as people with disabilities in Uganda

- Support and emphasize fistula prevention by promoting skilled birth attendance during antenatal care visits along with timely access to emergency obstetric care and reducing disrespect and abuse during childbirth, to dispel fears about medical care.

- Promote respectful maternity care to prevent obstetric fistula and promote future care seeking for fistula repair. 


\section{References}

Bellows, B., R. Bach, Z. Baker, C. Warren. 2015. Barriers to Obstetric Fistula Treatment in Low-income Countries: A Systematic Review. Nairobi: Population Council.

Uganda Bureau of Statistics (UBOS) and ICF International Inc. 2012. Uganda Demographic and Health Survey (UDHS) 2011. Kampala and Calverton, Maryland: UBOS and ICF International Inc.

Thaddeus, S. and D. Maine. 1994. Too Far to Walk: Maternal Mortality in Context. Soc Sci Med 38(8): 10911110.

Government of Uganda, Ministry of Health, National Obstetric Fistula Strategy (NOFS) 2011/2012 2015/2016 (policy document)

Government of Uganda, Ministry of Health, Health Sector Strategic Plan III (HSSP-III), 2010/11 - 2014/15 (policy document) 